\title{
Mortgage Krizi Öncesi ve Sonrasında Enflasyon - Faiz Etkileşimi: Türkiye Örneği
}

\section{Inflation - Interest Interaction Before and After the Mortgage Crisis: The Case of Turkey}

\author{
Ahmet Tayfur Akcan ${ }^{\mathrm{a}^{*}}$ \\ ${ }^{a}$ Dr. Öğr. Üyesi, Necmettin Erbakan Üniversitesi Uygulamalı Bilimler Fakültesi, Uluslararası Ticaret Bölümü/ 42100 KONYA \\ ORCID: 0000-0001-8210-7327
}

\section{MAKALE BİLGİSI}

Makale Geçmişi:

Başvuru tarihi: 17 Ağustos 2018

Düzeltme tarihi: 02 Ocak 2019

Kabul tarihi: 23 Ocak 2019

Anahtar Kelimeler:

Fisher Hipotezi,

Enflasyon,

Faiz,

Nedensellik

\section{ART ICLE INFO}

\section{Article history:}

Received 17 August 2018

Received in revised form 02 January 2019

Accepted 23 January 2019

\section{Keywords:}

Fisher Hypothesis,

Inflation,

Interest,

Causality

\section{ÖZ}

Enflasyon ve faiz oranları arasındaki ilişki birçok çalışmanın konusunu oluşturmaktadır. $\mathrm{Bu}$ çalışmalarda çoğunlukla Fisher Hipotezi üzerinedir. Fisher Hipotezi, reel faiz oranlarının uzun dönemde değişmeyeceği varsayımında, nominal faiz ile beklenen enflasyon oranının uzun dönemli ilişkili olacağını ileri sürmektedir. Çalışmada, Mortgage krizi öncesi ve sonrasında enflasyon ve işsizlik arasındaki nedensellik ilișkisi ve Fisher Hipotezinin geçerliliği araștırılmıștır. Haziran 2000 - Eylül 2007 ve Ekim 2007 - Ekim 2018 arası aylık veriler Augmented Dickey Fuller Birim Kök, Johansen Eşbütünleşme, ve Granger Nedensellik Testi ile analiz edilmiştir. Çalışmanın sonuçlarına göre; Mortgage Krizi öncesi, sonrası ve 2000-2018 arasında Fisher Hipotezi geçerlidir. Ancak Mortgage krizi öncesi değişkenler arasında var olan çift yönlü nedensellik ilişkisi kriz sonrasında kaybolmuştur. 2000-2018 dönemi arasında ise faiz oranlarından enflasyona doğru nedensellik ilişkisi tespit edilmiştir.

\begin{abstract}
A B S T R A C T
The relationship between inflation and interest rates is the subject of many studies. These studies are mostly about the Fisher Hypothesis. The Fisher hypothesis suggests that the nominal interest rate and the inflation rate will be in a long-run relationship under the assumption that real interest rates will not change. In this study, the causality relationship between inflation and unemployment and the validity of the Fisher Hypothesis were investigated before and after the mortgage crisis. June 2000 - September 2007 and October 2007 - October 2018 Monthly data were analyzed by Augmented Dickey Fuller Root Test, Johansen Cointegration Test and Granger Causality Test. According to the results of the study; The Fisher Hypothesis is valid before, after the crisis and during June 2000 - October 2018. However, the two-way causality relationship between the variables before the mortgage crisis was lost after the crisis. The causality relationship from interest rates to inflation was determined between June 2000 - October 2018.
\end{abstract}

\section{Giriş}

Enflasyon ve faiz oranları arasındaki ilişki, Türkiye Ekonomisi açısından en fazla tartışılan konular arasındadır. Özellikle Türkiye gibi gelişmekte olan ülkelerde, enflasyon ve faiz etkileşimi, sürdürülebilir ekonomik büyüme açısından da önem arz etmektedir. Faiz ve enflasyon politikalarının birbiri ile çelişmesi, uygulanan ekonomi politikalarının verimlilik ve etkinliğini azaltacaktır. $\mathrm{Bu}$ bakımdan söz konusu değişkenlerin birbiri ile korelasyonunun tespit edilmesi, uygulanan ekonomi politikalarının planlanması ve başarı olasılığının artmasına neden olacaktir.
Enflasyon ve faiz oranı arasındaki ilişkiyi sistematik olarak ilk inceleyen Irving Fisher'dir (Fisher: 1930). I. Fisher enflasyon ve faiz arasındaki uzun dönemli ilişkiyi incelemiş ve uzun dönemde enflasyon ve faiz oranları arasında ilişki olduğunu savunan Fisher Hipotezi literatüre kazandırılmıştır. Ancak Fisher söz konusu değişkenlerin nedensel ilişki boyutu ile ilgili herhangi bir çıkarımda bulunmamıştır.

Çalışmanın amacı Türkiye'de 2008 Küresel Mortgage Krizi öncesi ve sonrasında enflasyon ve faiz oranı değişkenlerinin etkileşiminde herhangi bir değişimin meydana gelip

*Sorumlu yazar/Corresponding author

e-posta: tayfurakcan@ hotmail.com 
gelmediğini hem Fisher Hipotezi hem de enflasyon ve faiz oranlarının nedensellik boyutunu analiz etmektir.

Türkiye ekonomisinde enflasyon ve faiz oranları arasındaki ilişkinin araştırılması için, Türkiye Cumhuriyet Merkez Bankası Elektronik Veri Dağıtım Sistemi’nden 2000 yılı Haziran ayı ve 2018 yılı Ekim ayı arası periyotta gerçekleşen bir ay vadeli dolar mevduat hesabına uygulanan faiz oranları ve yurt dışı üretici fiyat endeksleri kullanılmıştır. Ulusal Ekonomik Araştırmalar Bürosu (National Bureau of Economic Research, NBER) küresel krizin başlangıç noktasını 2007 yılının 3. Çeyreğinin sonu, 4. Çeyreğinin başı olarak kabul ettiği için, veri seti 2007 yılı Eylül ayı itibari ile ikiye ayrılmıştır. Daha önce yapılan çalışmaların araştırılması aşamasında, Türkiye için enflasyon ve faiz değişkenlerinin, 2008 krizi öncesi ve sonrasının analiz edildiği çalışmaya rastlanmadığı için, çalışmanın literatüre katkı sağladığı düşünülmektedir.

\section{Enflasyon-Faiz İlişkisi ve Fisher Hipotezi}

Faiz ve enflasyon oranı arasındaki ilişkiye, ilk olarak 1930 yılında Irving Fisher tarafından "Faiz Teorisi" kitabında değinilmiştir. Fisher'e göre, nominal faiz oranları, beklenen enflasyondaki değişmeye duyarlı hareket etmekte, ancak reel faiz oranları, beklenen enflasyon oranındaki değişmelere duyarsız kalmaktadır. Nominal faiz oranı ile beklenen enflasyon oranı arasındaki bu ilişkiye "Fisher Hipotezi" denilmektedir.

Fisher Hipotezi'nin formülize edilmiş hali; " $i_{t}=r_{t}+\pi_{t}^{e}$ " şeklinde gösterilmektedir. Bu formülasyonda; "i”" nominal faiz oranını, " $r$ " reel faiz oranını, $\pi^{\mathrm{e}}$ beklenen enflasyon oranını temsil etmektedir. Ancak ekonometrik modelleme açısından uygulamalarda, geçmişe dönük beklenen enflasyon oranının tespit edilmesi ve modele dahil edilmesi mümkün olmamaktadır. Bu sebeple "Rasyonel Beklentiler
Hipotezi” gereğince, beklenen enflasyon oranını temsil etmek üzere gerçekleşen enflasyon oranı kullanılmaktadır. Beklenen enflasyon oranı yerine gerçekleşen enflasyon oranının kullanılmasından dolayı Fisher Hipotezi formülasyonuna sifır ortalamaya sahip hata terimi de eklenerek " $i_{t}=r_{t}+\pi_{t}^{e}+\varepsilon_{t}$ " nihai halini almaktadır. Çalışmada beklenen enflasyon oranı yerine gerçekleşen cari enflasyon oranı kullanıldığından, Fisher Hipotezi "Rasyonel Beklentiler Hipotezi'nin” geçerliliği varsayımı altında analiz edilmektedir.

2008 Mortgage Krizi, Amerika Birleşik Devletleri'nde başlamış ve kısa sürede domino etkisi ile dünya geneline yayılmıştır. Bankalar tarafından düşük gelir grubuna (subprime) kullandırılan konut kredi taksitlerinin geri ödenememesinden kaynaklanan küresel kriz, en fazla bankacılık ve finans sektörlerini etkilemiştir. Finans sektöründe meydana gelen etkiler sebebi ile bazı makroekonomik değişkenlerin birbiri ile etkileşimi de değişime uğramıştır.

\section{Literatür Taraması}

Çalışmanın bu bölümünde Fisher Hipotezinin geçerliliğine yönelik yapılan çalışmalara yer verilmiştir. Fisher Hipotezinin testine yönelik çalışmalar tablo 1'de listelenmiştir. Literatür taramasında görülmektedir ki, özellikle Türkiye ekonomisi üzerinde yapılan çalışmaların hepsinde, Fisher Hipotezinin geçerli olduğu sonucuna ulaşılmıştır. Yapılan çalışmalara bakıldığında, Amerika Birleşik Devletleri, Birleşik Krallık, Almanya ve Kanada gibi gelişmiş ülkelerde, Fisher Hipotezinin geçerli olmadığı görülmektedir. Türkiye için ise Fisher hipotezinin geçerliliğine yönelik yapılan çalışmalarda ise genellikle Fisher Hipotezi'nin geçerli olduğu sonucuna ulaşılmıştır

Tablo 1: Fisher Hipotezinin Testine Yönelik Literatür Taraması

\begin{tabular}{|c|c|c|c|}
\hline Yazar & Yil & Ülke & Sonuç \\
\hline Fama & 1975 & Amerika Birleşik Devletleri & Fisher Hipotezi Geçerlidir \\
\hline Mishkin & 1984 & OECD Ülkeleri & Fisher Hipotezi Geçerlidir \\
\hline MacDonald ve Murphy & 1989 & $\begin{array}{l}\text { Amerika, Kanada, Belçika ve } \\
\text { İngiltere }\end{array}$ & Fisher Hipotezi Geçerlidir \\
\hline Woodward & 1992 & Birleşik Krallık & Fisher Hipotezi Geçerli Değildir \\
\hline Dutt ve Ghosh & 1995 & Kanada & Fisher Hipotezi Geçerli Değildir \\
\hline Wiedmann & 1997 & Almanya & Fisher Hipotezi Geçerli Değildir \\
\hline Lanne & 2001 & Amerika Birleşik Devletleri & Fisher Hipotezi Geçerli Değildir \\
\hline Juntilla & 2001 & Finlandiya & Fisher Hipotezi Geçerli Değildir \\
\hline Çakmak, Aksu ve Başar & 2002 & Türkiye & Fisher Hipotezi Geçerlidir \\
\hline Kutan ve Aksoy & 2004 & Türkiye & Fisher Hipotezi Geçerlidir \\
\hline Turgutlu & 2004 & Türkiye & Fisher Hipotezi Geçerlidir \\
\hline Şimşek ve Kadılar & 2006 & Türkiye & Fisher Hipotezi Geçerlidir \\
\hline Bolatoğlu & 2006 & Türkiye & Fisher Hipotezi Geçerlidir \\
\hline Gül ve Açıkalın & 2008 & Türkiye & Fisher Hipotezi Geçerlidir \\
\hline Westerlund & 2008 & OECD Ülkeleri & Fisher Hipotezi Geçerlidir \\
\hline Y1lanc1 & 2009 & Türkiye & Fisher Hipotezi Geçerli Değildir \\
\hline Ahmad & 2010 & Kuveyt & Fisher Hipotezi Geçerlidir \\
\hline Badillo, Reverte ve Rubio & 2011 & Avrupa Birliği Ülkeleri & Fisher Hipotezi Geçerlidir \\
\hline Köse, Emirmahmutoğlu ve Aksoy & 2012 & Türkiye & Fisher Hipotezi Geçerlidir \\
\hline İncekara, Ustaoğlu ve Aksoy & 2012 & Türkiye & Fisher Hipotezi Geçerlidir \\
\hline Mercan & 2013 & Türkiye & Fisher Hipotezi Geçerlidir \\
\hline Bayat, Kayhan ve Doğan & 2013 & BRIC - Türkiye & Fisher Hipotezi Geçerlidir \\
\hline Uçak, Öztürk ve Aslan & 2014 & Avrupa Birliği Ülkeleri & Fisher Hipotezi Geçerlidir \\
\hline Zainal, Nassır ve Yahya & 2014 & Malezya & Fisher Hipotezi Geçerlidir \\
\hline Köksel ve Destek & 2015 & Türkiye & Fisher Hipotezi Geçerlidir \\
\hline Takayasu & 2015 & İsveç & Fisher Hipotezi Geçerlidir \\
\hline
\end{tabular}




\begin{tabular}{llll}
\hline Yazar & Yıl & Ülke & Sonuç \\
\hline Kanca, Üzümcü ve Deniz & 2015 & Türkiye & Fisher Hipotezi Geçerlidir \\
\hline Lebe ve Özalp & 2016 & Türkiye & Fisher Hipotezi Geçerlidir \\
\hline Akıncı ve Yılmaz & 2016 & Türkiye & Fisher Hipotezi Geçerlidir \\
\hline Caporale ve Alana & 2017 & G-7 Ülkeleri & Fisher Hipotezi Geçerli Değildir \\
\hline Ümit & 2017 & Türkiye & Fisher Hipotezi Geçerlidir. \\
\hline
\end{tabular}

\section{Yöntem}

\subsection{Veri Seti}

Çalışmada Türkiye Cumhuriyet Merkez Bankası Elektronik Veri Dağıtım Sistemi veri havuzundan faydalanılarak, Haziran 2000 - Ekim 2018 tarihleri arasındaki bir ay vadeli dolar mevduat hesabına uygulanan faiz oranları ve yurt dişı üretici fiyat endeksi değerleri kullanılmıştır. Veri seti küresel kriz öncesi ve sonrası olmak üzere Haziran 2000 Eylül 2007, Ekim 2007 - Ekim 2018 tarihleri arası şeklinde ikiye ayrılmıştır. Yurt Dışı ÜFE değişkeni endeks değer olduğu için logaritması alınarak eşitliğe dahil edilmiştir. Veri setleri mevsimsel etki içerdiğinden öncelikle mevsimsellikten arındırılmıştır. Haziran 2000 - Eylül 2007 tarihleri arası veri seti kriz öncesini temsil ettiğinden KOENFLASYON ve KOFAIZ olarak adlandırılmıştır. Ekim 2007 - Ekim 2018 dönemini temsil eden veri seti ise kriz sonrası olduğu için KSENFLASYON ve KSFAİZ olarak adlandırılmıştır. Son olarak enflasyon ve faizin genel olarak ilişkilerinin incelenmesi için ise Haziran 2000 Ekim 2018 dönemi arası veriler GENFSLAYON ve GFAİZ olarak adlandırılmıştır. Bu kapsamda kurulan modeller aşağıdaki gibidir.

$\Delta \mathrm{KOFAIZZ}=\beta_{0}+\beta_{1} \operatorname{logKOENFLASYON}+\varepsilon_{\mathrm{t}}$

$\Delta \mathrm{KSFAIZ}=\beta_{0}+\beta_{1} \log \mathrm{KSENFLASYON}+\varepsilon_{\mathrm{t}}$

$\Delta \mathrm{GFAIZ}=\beta_{0}+\beta_{1} \operatorname{logGENFLASYON}+\varepsilon_{\mathrm{t}}$

1 numaralı eşitlik kriz öncesini, 2 numaralı eşitlik kriz sonrasını ve 3 numaralı eşitlik ise 2000-2018 kümülatif olarak enflasyon ve faiz ilişkisini analiz etmek için kullanılmıştır.

\subsection{Augmented Dickey Fuller (ADF) Birim Kök}

\section{Testi}

Zaman serilerinde sürekli artış ya da sürekli azalış trendlerinin varlığı durumu, değişkenler arasında olmayan ilişkinin söz konusu trendler sebebi ile varmış gibi görünmesine, dolayısıyla sahte regresyon çıkmasına sebep olmaktadır. Bu nedenle değişkenler ekonometrik testlere tabi tutulmadan önce sahte regresyonların oluşmasının önlenmesi için birim kök testi ile incelenmektedir. Birim kök testlerinin ilki 1979 yılında D. Dickey ve W. Fuller tarafindan bulunmuştur. Bulunan bu test iki yıl sonra geliştirilerek son halini almış ve Augmented Dickey Fuller Birim Kök Testi olarak literatüre girmiştir (Dickey ve Fuller: 1981).

Augmented Dickey Fuller Birim Kök testinde zaman serisi değişkenlerinde trend gözlendiğinden, trend içeren serilerde durağanlık analizi için kullanılan4 numaralı eşitlik ile durağanlık durumları analiz edilmiştir.

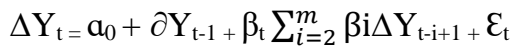

Augmented Dickey Fuller Birim Kök Testi temelde, yukarıda geçen denklemlerdeki $\partial$ katsayısının tahmin değerinin ve standart hata değerinin En Küçük Kareler yöntemini kullanarak hesaplamaya dayanmaktadır. Söz konusu denklemlerle hesaplanan test değerleri D. Dickey ve W. Fuller tarafindan oluşturulan tablodaki ilgili değerlerle kıyaslanmaktadır. $\mathrm{Bu}$ kıyaslama da temel amaç $\partial=0$ eşitliğinin sağlanıp sağlanmadığına bakmaktır. $\partial$ değerine bağlı kurulan hipotezler aşağıdaki gibidir.

$$
\begin{array}{lll}
\mathrm{H}_{0}=\partial=0 & \text { Seri durağan değildir, } & \\
\mathrm{H}_{1}=\partial<0 & \text { Seri } \quad \text { durağandır } & \text { sonucu }
\end{array}
$$

çıkarılmaktadır.

\subsection{Johansen Eşbütünleşme Testi}

Eşbütünleşme analizi zaman serilerinde, değişkenlerin arasında uzun dönemde herhangi bir ilişkinin olup olmaması durumunu analiz etmektedir. Johansen Eşbütünleşme Testinin uygulanabilmesinin ön koşulu serilerin aynı dereceden durağan olması gerekliliğidir. Johansen Eşbütünleşme testinde temel olarak iki denklem kullanılmakta olup, bu denklemler5 ve 6 numaralı eşitlikler olarak aşağıdadır (Johansen: 1988).

$$
\begin{aligned}
& \mathrm{y}_{\mathrm{t}}=\alpha_{1} \mathrm{y}_{\mathrm{t}-1}+\ldots+\alpha_{\mathrm{k}} \mathrm{y}_{\mathrm{t}-\mathrm{k}}+\varepsilon_{\mathrm{t}}, \mathrm{t}=1,2, \ldots, \mathrm{T}(5) \\
& \Delta \mathrm{y}_{\mathrm{t}}=\sum_{i=2}^{k-1} \Gamma \Delta \mathrm{y}_{\mathrm{t}-\mathrm{i}}+\prod \mathrm{y}_{\mathrm{t}-\mathrm{k}+} \varepsilon_{\mathrm{t}}
\end{aligned}
$$

Yukarıdaki eşitlikler ile iz istatistiği ve maksimum öz değer hesaplanmaktadır. Hesaplanan iz değeri ve maksimum öz değer \%5 güvenilirlik düzeyi için hesaplanan test istatistiğinden büyük olması halinde, değişkenler arasında eşbütünleşik ilişkinin varlığı ortaya çıkmaktadır. Ancak tersi olması durumunda ise değişkenler arasında eşbütünleşik ilişkinin olmadığı dolayısıyla uzun dönemli ilişkiden bahsedilemeyeceği sonucu ortaya çıkmaktadır.

\subsection{Granger Nedensellik Testi}

Nedensellik testleri iki değişken arasındaki neden yönünün araştırılması için tasarlanmış testlerdir. Literatürde kullanılan en yaygın test ise 1986 yılında oluşturulan ve 1987 yılında geliştirilen Granger Nedensellik testidir. Değişkenler arasındaki nedensellik yönünün tespit edilmesi için ise 7 ve 8 numaralı eşitlikler kullanılmaktadır.

$\mathrm{Y}_{\mathrm{t}}=\sum_{i=1}^{m} \mathrm{aiYt}-\mathrm{i}+\sum_{i=1}^{m} \beta \mathrm{iYt}-\mathrm{i}+\varepsilon_{1 \mathrm{t}}$

$\mathrm{X}_{\mathrm{t}}=\sum_{i=1}^{m} \theta \mathrm{iXt}-\mathrm{i}+\sum_{i=1}^{m} \gamma \mathrm{iYt}-\mathrm{i}+\varepsilon_{2 \mathrm{t}}$

Haziran 2000 - Ekim 2018 enflasyon ve faiz oranına ait değişkenler ilk önce birim kök testine tabi tutulmuştur. Ardından VAR analizi ile uygun gecikmelerinin tespit edilmesinden sonra uzun dönem ilişkilerinin analizi için Johansen Eşbütünleşme testi ve nedenselliklerinin analizi için ise Granger Nedensellik testine tabi tutulmuştur. Bu testlerde ulaşılan değerler, ampirik bulgular başlığı altında raporlanmıştır. 


\section{Ampirik Bulgular}

Kriz öncesi, kriz sonrası ve kümülatif olarak değerlendirilen veri setlerine ait durağanlık analizi sonuçları tablo 2'de verilmektedir.

Tablo 2: Augmented Dickey Fuller Birim Kök Testi Bulguları

\begin{tabular}{|c|c|}
\hline Değişken & $\begin{array}{l}\text { Trend ve sabit terimli \%5 Değeri } \\
\text { (Test İstatistiği) } \\
\text { [Olasılık Değeri] }\end{array}$ \\
\hline KÖEnflasyon & $\begin{array}{l}-3,463547 \\
(-2,256111) \\
{[0,4527]}\end{array}$ \\
\hline \KÖEnflasyon & $\begin{array}{l}-3,463912 \\
(-4,688006) \\
{[0,0015]}\end{array}$ \\
\hline KÖFaiz & $\begin{array}{l}-3,470032 \\
(-2,669968) \\
{[0,2519]}\end{array}$ \\
\hline$\Delta K O ̈ F a i z$ & $\begin{array}{l}-3,470851 \\
(-7,508165) \\
{[0,0000]}\end{array}$ \\
\hline KSEnflasyon & $\begin{array}{l}-3,444487 \\
(-0,810174) \\
{[0,9613]}\end{array}$ \\
\hline$\Delta$ KSEnflasyon & $\begin{array}{l}-3,444487 \\
(-7,142936) \\
{[0,0000]}\end{array}$ \\
\hline KSFaiz & $\begin{array}{l}-3,444487 \\
(-1,398958) \\
{[0,8570]}\end{array}$ \\
\hline$\Delta$ KSFaiz & $\begin{array}{l}-3,444487 \\
(-8,784803) \\
{[0,0000]}\end{array}$ \\
\hline GEnflasyon & $\begin{array}{l}-3,430477 \\
(-4,888479) \\
{[0,0004]}\end{array}$ \\
\hline GFaiz & $\begin{array}{l}-3,431062 \\
(-4,914685) \\
{[0,0004]}\end{array}$ \\
\hline
\end{tabular}

Tablo 2'deki değişkenlere ait birim kök testi sonuçlarına göre; kriz öncesi ve sonrası enflasyon ve faiz oranı değişkenleri, birinci farklarında durağan çıkmakta ancak kriz öncesi ve sonrasının kesintisiz dahil edildiği veri seti ise düzey değerinde durağan çıkmaktadır. Bu nedenle ayrı modeller halinde incelenen kriz öncesi ve kriz sonrası enflasyon ve faiz oranı değişkenlerinin birinci dereceden farkları alınması suretiyle modele dahil edilmiştir.

Tablo 4'te ise üç farklı modele ait uygun gecikmeler gösterilmektedir. Modeller ayrı ayrı VAR analizine tabi tutulduğunda, Akaike, Schwarz ve Hannan-Quinn bilgi kriterlerine göre kriz öncesinde 4. gecikme, kriz sonrasında 2. gecikme ve kümülatif seride ise 7 . gecikmenin seçilmesi uygun görülmüştür. Modellerde bazen bilgi kriterleri farklı dereceleri uygun görmektedir. Böyle durumla karşılaşıldığında, en küçük değere sahip olan bil kriteri dikkate alınarak uygun gecikme uzunluğu belirlenmiştir.

Tablo 3: Uygun Gecikme Uzunlukları

\begin{tabular}{cccc}
\hline G.U & Akaike & Schwartz & Hannan-Quinn \\
\hline \multicolumn{4}{c}{ Haziran 2000 - Eylül 2007 } \\
\hline $\mathbf{0}$ & $-4,845325$ & $-4,787039$ & $-4,821909$ \\
\hline $\mathbf{1}$ & $-5,715716$ & $-5,540860$ & $-5,645468$ \\
\hline $\mathbf{2}$ & $-5,846108$ & $-5,554682$ & $-5,729029$ \\
\hline $\mathbf{3}$ & $-6,205494$ & $-5,797496^{*}$ & $-6,041583$ \\
\hline
\end{tabular}

\begin{tabular}{cccc}
\hline $\mathbf{4}$ & $-6,313057^{*}$ & $-6,313057$ & $-6,102315^{*}$ \\
\hline \multicolumn{4}{c}{ Ekim 2007 - Ekim 2018 } \\
\hline $\mathbf{0}$ & $-8,720477$ & $-8,676361$ & $-8,702551$ \\
\hline $\mathbf{1}$ & $-8,962119^{*}$ & $-8,829771^{*}$ & $-8,908342^{*}$ \\
\hline $\mathbf{2}$ & $-8,676361$ & $-8,724252$ & $-8,855203$ \\
\hline \multicolumn{4}{c}{ Haziran 2000 - Ekim 2018 } \\
\hline $\mathbf{0}$ & 2,186576 & 2,218668 & 2,199552 \\
\hline $\mathbf{1}$ & $-8,050042$ & $-7,953767$ & $-8,011113$ \\
\hline $\mathbf{2}$ & $-8,525746$ & $-8,365287$ & $-8,460865$ \\
\hline $\mathbf{3}$ & $-8,523043$ & $-8,298401$ & $-8,432209$ \\
\hline $\mathbf{4}$ & $-8,596731$ & $-8,307906$ & $-8,479945$ \\
\hline $\mathbf{5}$ & $-8,751456$ & $-8,398447$ & $-8,608717$ \\
\hline $\mathbf{6}$ & $-9,056970$ & $-8,639778^{*}$ & $-8,888279^{*}$ \\
\hline $\mathbf{7}$ & $-9,077366^{*}$ & $-8,596490$ & $-8,883222$ \\
\hline
\end{tabular}

Bu gecikme değerleri baz alındığından kurulan modellerde ise Johansen Eşbütünleşme Testi sonuçları tablo 4'de verilmiştir.

Tablo 4: Johansen Eşbütünleşme Testi Bulguları

\begin{tabular}{|c|c|c|c|c|}
\hline \multicolumn{5}{|c|}{ Haziran 2000 - Eylül 2007} \\
\hline Test & Özdeğer & $\begin{array}{l}\text { İz Değeri } \\
\text { veya } \\
\text { Maksimum } \\
\text { Öz Değeri }\end{array}$ & $\begin{array}{c}\% 5 \text { Kritik } \\
\text { Değeri }\end{array}$ & $\begin{array}{l}\text { Olasılık } \\
\text { Değeri }\end{array}$ \\
\hline İz Testi & 0,201714 & 24,12080 & 12,32090 & 0,0004 \\
\hline $\begin{array}{c}\text { Maksimum } \\
\text { Öz Değer } \\
\text { Tetsi }\end{array}$ & 0,201714 & 18,47368 & 11,22480 & 0,0023 \\
\hline \multicolumn{5}{|c|}{ Ekim 2007 - Ekim 2018} \\
\hline İz Testi & 0,326575 & 72,17663 & 20,26184 & 0,0000 \\
\hline $\begin{array}{c}\text { Maksimum } \\
\text { Öz Değer } \\
\text { Tetsi }\end{array}$ & 0,326575 & 51,00386 & 15,89210 & 0,0000 \\
\hline \multicolumn{5}{|c|}{ Haziran 2000 - Ekim 2018} \\
\hline İz Testi & 0,176054 & 45,11670 & 25,87211 & 0,0001 \\
\hline $\begin{array}{c}\text { Maksimum } \\
\text { Öz Değer } \\
\text { Tetsi }\end{array}$ & 0,176054 & 40,08564 & 19,38704 & 0,0001 \\
\hline
\end{tabular}

Yukarıdaki sonuçlar değerlendirilirken en kolay yol olasılık değerlerine göre yorumlamaktır. Eğer modele ait olasılık değeri 0,05 değerinden küçükse $\mathrm{H}_{0}$ hipotezi reddedilmekte, $\mathrm{H}_{1}$ hipotezi ise kabul edilmektedir. Söz konusu hipotezler ise aşağıdaki gibidir.

$\mathrm{H}_{0}=$ Değişkenler arasında eşbütünleşme ilişkisi yoktur.

$\mathrm{H}_{1}=$ Değişkenler arasında eşbütünleşme ilişkisi vardır.

Tablo 5: Granger Nedensellik Testi Sonuçları

\begin{tabular}{|c|c|c|c|}
\hline Hipotez & Ki Kare & Gecikme & Olasılık \\
\hline \multicolumn{4}{|c|}{ Haziran 2000 - Eylül 2007} \\
\hline Enflasyon $\rightarrow$ Faiz & 55,50748 & 4 & 0,0000 \\
\hline Faiz $\rightarrow$ Enflasyon & 12,00602 & 4 & 0,0173 \\
\hline
\end{tabular}

Ekim 2007 - Ekim 2018

\begin{tabular}{|c|c|c|c|}
\hline Enflasyon $\rightarrow$ Faiz & 2,073058 & 1 & 0,1499 \\
\hline Faiz $\rightarrow$ Enflasyon & 0,287602 & 1 & 0,5918 \\
\hline \multicolumn{4}{|c|}{ Haziran 2000 - Ekim 2018} \\
\hline Enflasyon $\rightarrow$ Faiz & 13,28687 & 7 & 0,0654 \\
\hline Faiz $\rightarrow$ Enflasyon & 81,72928 & 7 & 0,0000 \\
\hline
\end{tabular}

Tablo 5'e göre kriz öncesi dönemde enflasyon ve faiz oranları arasında çift yönlü nedensellik ilişkisi mevcuttur. Kriz sonrası dönemde ise söz konusu çift yönlü nedensellik ilişkisinin ortadan kalktığı görülmektedir. Ancak Haziran 
2000 ve Ekim 2018 arası dönem kümülatif olarak incelendiğinde ise $\% 95$ güven düzeyinde faiz oranlarının enflasyonun nedeni olduğu görülmektedir. Ancak güven düzeyi $\% 90$ olarak kabul edildiğinde ise enflasyon ve faiz oranları arasındaki çift yönlü nedensellik ilişkisinin olduğu sonucu ortaya çıkmaktadır.

\section{Sonuç}

Enflasyon, faiz, istihdam ve ekonomik büyüme değişkenleri makroekonomik performans kriterlerinin en önemlilerindendir. Bu nedenle söz konusu değişkenlere yönelik çok sayıda çalışma yapılmış ve aralarındaki ilişki araştırılmıştır. $\mathrm{Bu}$ çalışmada da Türkiye ekonomisinde enflasyon ve faiz oranları arasındaki ilişki araştırılmıştır. Araştırmadan elde edilen ilk bulgu, literatürle de mükemmel uyum sağlamaktadır. Türkiye ekonomisinden 2008 yılında yaşanan küresel Morgage krizi öncesinde ve sonrasinda da enflasyon ve faiz oranları arasında uzun dönemli eşbütünleşik ilişkinin olduğudur. Dolayısıyla Türkiye'de 2008 Küresel Mortgage krizi öncesi ve sonrasında Fisher Hipotezi geçerlidir.

Fisher Hipotezinin geçerli olduğu ekonomilerde, faiz oranı ve para arzı ile enflasyon oranı hedeflerinin tutturulması mümkün olabilmektedir. Özellikle Türkiye gibi fiyat istikrarının önemli olduğu ülkelerde, Merkez Bankaları'nın uyguladığı politikalar önem kazanmaktadır.

Çalışmadan elde edilen ikinci bulgu ise değişkenlerin arasındaki nedensellik ilişkisi kapsamındadır. 2008 yılında yaşanan Mortgage krizinden önce enflasyon ve faiz oranları arasındaki çift yönlü nedensellik ilişkisi, kriz sonrası dönemde kaybolmuştur. Ancak söz konusu ilişki 2000-2018 yılları arası periyoda bakıldığında \%90 güven seviyesinde mevcut durumda iken, \%95 seviyesinde sadece faizden enflasyona doğru bir nedensellik olduğu sonucu ortaya çıkmaktadır. Bu kapsamda çıkarılan net sonuç ise zamanla enflasyonun faize neden olma durumu etkisini kaybetmektedir.

Faizlerin enflasyonun nedeni olması ve bu etkinin zamanla artması, Merkez Bankası'nın en önemli aracı olan politika faizinin, öncelikli amacı olan fiyat istikrarının sağlanması hedefinde daha önemli hale getirmektedir. Hatalı uygulanan faiz politikaları ekonomide enflasyonist etki oluşturacak ve enflasyonist süreç ise Merkez Bankasının başarısız olmasına sebep olacaktır. Dolayısıyla Merkez Bankası'nın bağımsızlığı, doğrudan başarısı ile ilgili olmaktadır.

\section{Kaynakça}

Ahmad, S. (2010) "The Long Run Fisher Effect in Developing Countries", Studies in Economics and Finance, 27 (4), 268-275

Akıncı M. ve Yılmaz, Ö. (2016), “Enflasyon- Faiz Oranı Takası: Fisher Hipotezi Bağlamında Türkiye Ekonomisi İçin Dinamik En Küçük Kareler Yöntemi”, Sosyoekonomi, 24(27), 33-55

Atgür, M, ve Altay, N. O. (2015) "Enflasyon ve Nominal Faiz Oranı İlişkisi: Türkiye Örneği (2004-2013)", Journal of Management \& Economics, 22(2). 521-533
Badillo, R. C. Reverte, E. Rubio, (2011), "The Fisher Effect in The EU Revisited: New Evidence Using Panel Cointegration Estimation With Global Stochastic Trends", Applied Economics Letters, 18, 1247-1251

Bayat, T. (2012), “Türkiye'de Fisher Etkisinin Geçerliliği: Doğrusal Olmayan Eşbütünleşme Yaklaşımı”, Erciyes Üniversitesi İktisadi ve İdari Bilimler FakültesiDergisi, 38, 47-60.

Bayat, T., Kayhan, S. ve Doğan, Ç. (2013) "BRIC-T Ülkelerinde Fisher Etkisinin Ampirik Olarak İncelenmesi" Íktisat İşletme ve Finans, 29(334), 95-120

Bolatoğlu, N. (2006), “Türkiye'de Enflasyon ve Nominal Faiz Oranları Arasındaki Uzun Dönemli İlişki: Fisher Etkisi”, H. ̈. İktisadi ve İdari Bilimler Fakültesi Dergisi, 24(2), 1-15

Caporale, G. M. ve Alana, L. A. G. (2017), "Testing the Fisher Hypothesis in the G-7 Countries Using I(d) Techniques, CESifo Working Paper Series No. 6482, 121

Çakmak, E., Aksu, H. ve Başar, S. (2002), "Fisher Hipotezinin Türkiye Açısından Değerlendirilmesi: 1989-2001", Atatürk Üniversitesi Iktisadi ve İdari Bilimler Dergisi, 16(3-4), 31-40.

Dickey, D. ve Fuller, W. (1979), "Distribution of The Estimators for Autoregressive Time Series With a Unit Root", Journal of The American Statistical Association, $74,427-431$.

Dickey, D. ve Fuller, W. (1981), "Likelihood Ratio Statistics For Autoregressive Time Series With a Unit Root", Econometrica, 49(4), 1057-1072

Dutt, S., D. Ghosh (1995), "The Fisher Hypothesis: Examining The Canadian Experience", Applied Economics, 27, 1025-1030.

Engle, R. ve Granger, C. (1987) "Co-İntegrationand Error Correction: Representation, Estimation And Testing", Journal Of Econometrica, 251-276

Fama, E. (1975), "Short-Term Interest Rates as Predictors of Inflation", American Economic Review, 65, 269-282.

Fisher, I. (1930), “The Theory of Interest", The Macmillan Company, New York. (http://www.econlib.org/library/YPDBooks/Fisher/fshT oI.html)

Gül, E., Açıkalın S. (2008), “An Examination of The Fisher Hypothesis: The Case of Turkey",Applied Economics, 40, 3227-3231.

İncekara A.; Demez, S. ve Ustaoğlu, M. (2012), "Validity of Fisher Effect for Turkish Economy: Cointegration Analysis", Procedia-Social and BehavioralSciences, 58: 396-405

Johansen, S. (1988), "Statistical Analysis of Cointegration Vectors", Journal of Economic Dynamics and Control, $12(2-3), 231-254$.

Juntilla, J. (2001), “Testing an Augmented Fisher Hypothesis for Small Open Economy: The Case of Finland", Journal of Macroeconomics, 23, 577-599. 
Kanca, O.C, Üzümcü, A, Deniz, A. (2015). "Fisher Etkisi Türkiye Ekonomisi İçin Geçerli Mí? Bir Zaman Serisi Analizi: 1980-2013", Verimlilik Dergisi, 3, 1-18

Köksel, B. ve Destek, M. A. (2015). “Türkiye Ekonomisinde Fisher Hipotezinin Test Edilmesi: 20022014 Dönemi Üzerine Bir Ampirik Analiz", The Journal ofInternational Social Research, 8(41), 12471253

Köse, N., Emirmahmutoğlu, F. ve Aksoy, S. (2012), "The Interest Rate-Inflation Relationship Underan Inflation Targeting Regime: The Case of Turkey", Journal of Asian Economics, 23, 476-485.

Kutan, A.M. ve Aksoy, T. (2003), "Public Information Arrival And The Fisher Effect In Emerging Markets: Evidence From Stock And Bond Markets In Turkey”, Journal of FinancialServices Research, 23(3), 225-239.

Lanne, M. (2001), "Near Unit Root and The Relationship Between Inflation and Interest Rates: a Reexamination of The Fisher Effect", Empirical Economies, 26, 357366.

Lebe F., Özalp, L. F. (2016), "Fisher Hipotezinin Alternatif Faiz Oranları ile Türkiye Ekonomisi Açısından Analizi”, Dokuz Eylül Üniversitesi İktisadi ve İdari Bilimler Fakültesi Dergisi, 33(1), 95-122

Macdonald, R., P. Murphy (1989), “Testing for The Long Run Relationship Between Nominal Interest Rate and Inflation Using Cointegration Techniques", Applied Economics, 21, 439-447.

Mercan, M. (2013), “Enflasyon Ve Nominal Faiz Oranları Arasındaki Uzun Dönem İlişkinin Fisher Hipotezi Çerçevesinde Test Edilmesi: Türkiye Örneği”, Atatürk ÜniversitesiIIIBF Dergisi, 27, 368-384.

Mishkin, F.S. (1984), “Are Real Interest Rates Equal Across Countries? an Empirical Investigation of International Parity Conditions", Journal of Finance, 39, 1345-1357.
Öruç E. (2016), "Fisher Etkisi: Türkiye Üzerine Bir Uygulama”, Kastamonu Üniversitesi Iktisadi Idari Bilimler Fakültesi Dergisi, 13, 297-311

Şimşek, M., Kadılar, C. (2006), "Fisher Etkisinin Türkiye Verileri İle Testi”, Doğuş Üniversitesi Dergisi, 7, 99111.

Takayasu, I., (2015), "Does the Fisher Hypothesis Hold in Sweden? An Analysis of Long-Term Interest Rates under the Regime of Inflation Targeting", Review of Integrative Business and Economics, 5(3), 283-295

Turgutlu, E. (2004), "Fisher Hipotezinin Tutarlılı̆̆ının Testi: Parçalı Durağanlık ve Parçalı Koentegrasyon Analizi”, Dokuz Eylül Üniversitesi İIBF Dergisi, 19, 5574.

Umit, A. O, (2017), "Empirical Analysis of Fisher Hypothesis fort he Period Following the Inflation Targeting Starategy in Turkey", International Journal of Economic Perspectives, 11(2), 97-109

Weidmann, J. (1997), "New Hope For The Fisher Effect?", Discussion Paper B-385, University of Bonn, Institut Für Internationale Wirtschaftspolitik, 1-25

Westerlund, J. (2008), "Panel Cointegration Tests Of The Fisher Effect", Journal of Applied Econometrics, 23, 193-223

Woodward G. T. (1992), "Evidence of The Fisher Effect From U.K. Indexed Bonds", The Review of Economics and Statistics, 315-320

Yılancı, V. (2009), "Fisher Hipotezinin Türkiye İçin Sınanmas1: Doğrusal Olmayan Eşbütünleşme Analizi”, Atatürk Üniversitesi İktisadi ve İdari Bilimler Dergisi, 23(4), 205-213.

Zainal, N., Nassır, A. M. D. ve Mohamed, H. Y. (2014). "Fisher Effect: Evidence From Money Market in Malaysia", Journal of Social Science Studies, 1(2), 112124 